\title{
A Virtual Learning Environment for Perioperative Continuing Nursing
}

\section{Education}

Toni McKenna, DNSc, RN ${ }^{\mathrm{a}, *}$, Sarah Jones, MA, MLS
This manuscript version

is a rendition of

the author's post review copy.

The official version of record

is available at the

Perioperative Nursing Clinics site.
Nursing Informatic

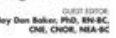

PERIOPERATIVE

NURSING

CUINICS

\section{KEYWORDS}

- Second Life $\bullet$ Continuing nursing education $\bullet$ Virtual world $\bullet$ Distance education

- Virtual learning environment

\section{KEY POINTS}

- Second Life is a virtual-world learning environment that can serve as a venue for creative and engaging continuing nursing education.

- A virtual world is an on-line, three-dimensional graphical, multimedia environment where individuals are represented by avatars (digital versions of self).

- Clinical educators in all nursing and healthcare specialties should be aware of the advantages and many potential uses of Second Life.

Exploring new worlds and creative approaches to delivering continuing education is an adventure worth taking! The basic requirement of content that advances the skills and abilities of the registered nurse (RN) can be met in a number of ways. What is clear though is that continuing education is most effective when the experience fully engages learners, expands their skills and knowledge, provides expert information and opportunity for networking, and entices them to learn more. ${ }^{1}$ This article describes how a virtual-world learning environment (Second Life, or SL) was used as a venue for an interactive and creative continuing nursing education activity and the positive outcomes that were achieved for the participants (Fig. 1).

\section{CHALLENGES OF CONTINUING EDUCATION}

Planning and providing continuing nursing education for specialty nursing groups can be challenging. There are time and space constraints as well as difficulties relieving

\footnotetext{
The authors have nothing to disclose.

a Center for Continuing Nursing Education, University of Texas Arlington, PO Box 19197, 140

West Mitchell Street, Arlington TX 76019, USA

${ }^{b}$ Digital Library Services, University of Texas at Arlington Library, PO Box 19497, 702 Planetarium

Place, Arlington, TX 76019, USA

* Corresponding author.

E-mail address: tmckenna@uta.edu
}

Perioperative Nursing Clinics 7 (2012) 237-250

doi:10.1016/i.cpen.2011.10.001

periopnursing.theclinics.com

(c) 2012 Elsevier Inc. All rights reserved. 


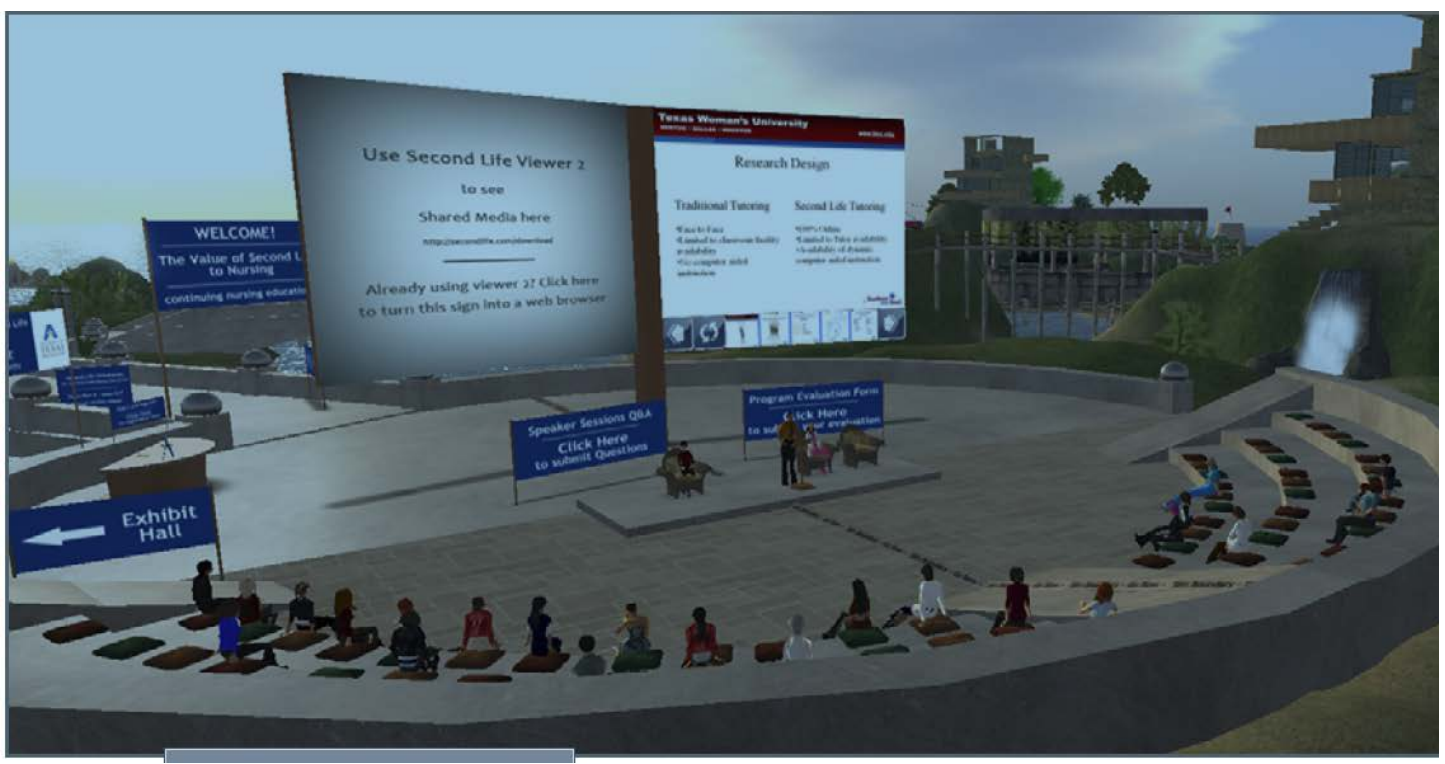

Fig. 1 The University of Texas at Arlington continuing nursing education conference workshop. (Courtesy of Sarah Jones.)

staff from their clinical responsibilities, providing adequate depth and applicability of the content, building and maintaining clear learning objectives, and securing expert presenters at the time and place needed. One major obstacle is fully engaging the nurse participants; the education must be impactful, making a difference in their knowledge and practice, and it needs to keep their interest. All of these aspects must occur in a relatively short time frame and at a very reasonable cost, given work and home time constraints and average attention span! ${ }^{2}$ Finding new and different ways to deliver continuing nursing education can have positive impacts on the quality of the education, the willingness and interest of the professional nurse, and the potential positive outcomes on patient care. The expense of travel and additional time to bring experts together to share their knowledge are further obstacles to providing continuing education. Use of a virtual world as the venue for continuing education can be one of the mechanisms for meeting these challenges. ${ }^{3}$

\section{WHAT IS A VIRTUAL WORLD?}

Virtual worlds connect people online in an immersive, engaging way that webcams, Skype, and Web conferencing alone cannot achieve. A virtual world is an online, three-dimensional (3-D) graphical, multimedia environment where individuals are represented by avatars (digital versions of the self). Characteristics of a virtual world ${ }^{4}$ include both synchronous and persistence elements.

\section{Synchronousness}

Synchronousness means that all participants at a location experience the same environment including the visual scene; the other participants in the form of their avatars; public text and voice chat; the animations of objects or avatars; sounds that come from the environment, objects in the environment or other avatars; and any public multimedia, including Web displays, that are in the environment. Additionally, any changes to the environment happen in real time, and those changes are observable in real time by all participants at the location. Synchronousness allows for live, dynamic demonstrations; participation in and observation of simulations and role-play; and real-time, dynamic, participatory activities in general. 


\section{Persistence}

Persistence means the environment persists even though a participant has left the location; that environment continues to exist without the necessity of the participant or other avatars being present in the virtual space. Persistence does not necessarily equate to staticness. Persons with the appropriate rights to alter the environment can introduce changes to the environment, which are then observable when a participant returns to that location.

\section{WHY IS A VIRTUAL WORLD A GOOD CHOICE FOR PERIOPERATIVE CONTINUING NURSING EDUCATION?}

Using a virtual world to deliver education content offers the opportunity for benefits beyond what Web conferencing or other online platforms can provide. Many online platforms can address issues related to travel and attendant time and cost to participants plus overhead expenses for use of a physical facility. In addition, online platforms allow a participant access to a global range of speakers, discussion groups, and professional networking opportunities. A virtual world, however, adds facets to the experience that other online platforms cannot: sense of self, sense of place, and sense of presence, which derive from the nature of the platform itself. Therefore, a 3D real-time shared experience can support and reinforce visually, aurally, and interactively the specific purpose and goals of the activities to be carried out. This 3-D immersive environment is combined with "being there" as an avatar with all other participants who are also present in avatar form. Together this experience leads to engagement that other online platforms cannot attain. ${ }^{5}$

\section{Sense of Self}

When a person is logged into a virtual world, that person is represented by an avatar that is highly customizable. Virtually all aspects of an avatar's appearance can be changed, from the size and shape of dozens of individual body parts to skin tone and shading, hair style and color as well as a vast range of choices available for avatar clothing and accessories (Fig. 2). As a result, it is possible to create a finely tuned representation of the self that reflects what the actual person wishes to project.6 Crafting this avatar to a person's preferences and experiencing the virtual world through that avatar leads to the sense that the avatar is the person directing itavatar as self rather than a separate "other."

\section{Sense of Place}

The 3-D, multisensory, realistic environment of a virtual world where a person is present as an avatar is key to providing an immersive experience. While embodied in the avatar, the person moves through virtual space and experiences virtual versions of objects, buildings, and outdoor scenes in a way that resembles, and then becomes analogous to, physical-world spaces. With the addition of community (others whose avatars also are present in the space), virtual world spaces become "third places" (gathering places, defined or casual, where people go to be in a social environment). ${ }^{7}$

\section{Sense of Presence}

Being an avatar in a 3-D immersive environment together with others who are similarly represented as avatars and sharing real-time interpersonal communication and the same visual and aural experiences in that environment leads to a sense of actually being there. ${ }^{8}$ An extension of this sense is the concept of "copresence," which describes avatar embodiment in a 3-D immersive, realistic, space in combination with 


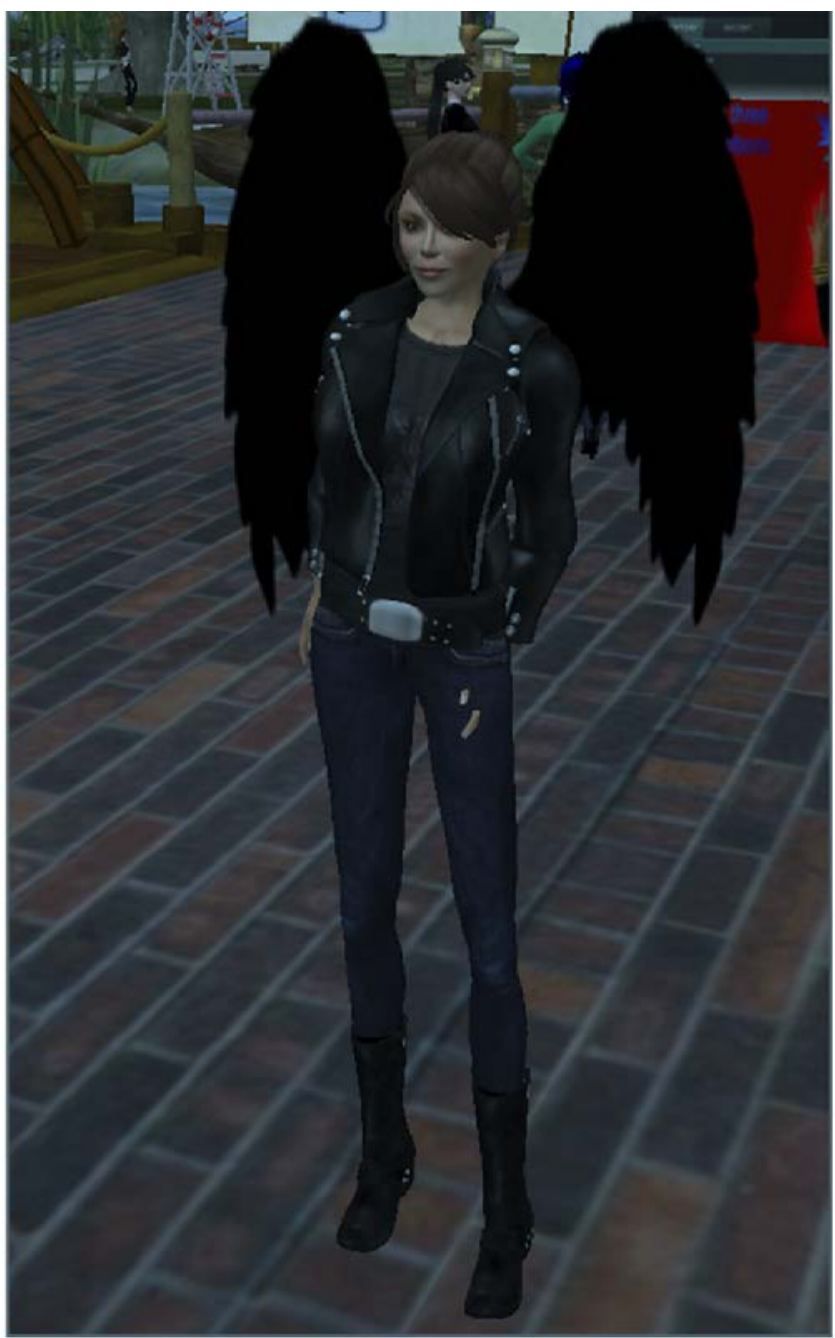

Fig. 2 Avatar in SL. (Courtesy of Sarah Jones.)

virtual face-to-face communication with others similarly embodied and is the sense that one is actually present with others despite the physical distance between them (Fig. 3). ${ }^{9}$

\section{WHAT IS SL?}

SL10 is a virtual-world platform created and owned by Linden Lab. ${ }^{11}$ SL opened to the public in June 2003. Over the 8 years of its existence, SL has been adopted as a platform for learning and outreach by hundreds of universities, colleges, schools, and libraries throughout the world. ${ }^{12}$

User statistics from Linden Lab for the first quarter of 2011 report 794,000 average monthly repeat logins, a rate that was stable over the October 2009 through March 2011 (fourth quarter 2009-first quarter 2011) reporting period. ${ }^{13}$ Typically, approximately 58,000 users are logged in at any given time. Whereas other virtual worlds have been used for nonrecreational purposes including World of Warcraft ${ }^{14,15}$ and Active Worlds, ${ }^{16}$ what distinguishes SL is that user-created content is at its foundation. As a result, it is possible to craft an environment on the SL platform to meet the specific needs of a given purpose. The combination of (1) online platform, (2) overcoming the barriers of distance and travel, (3) synchronous experience for 


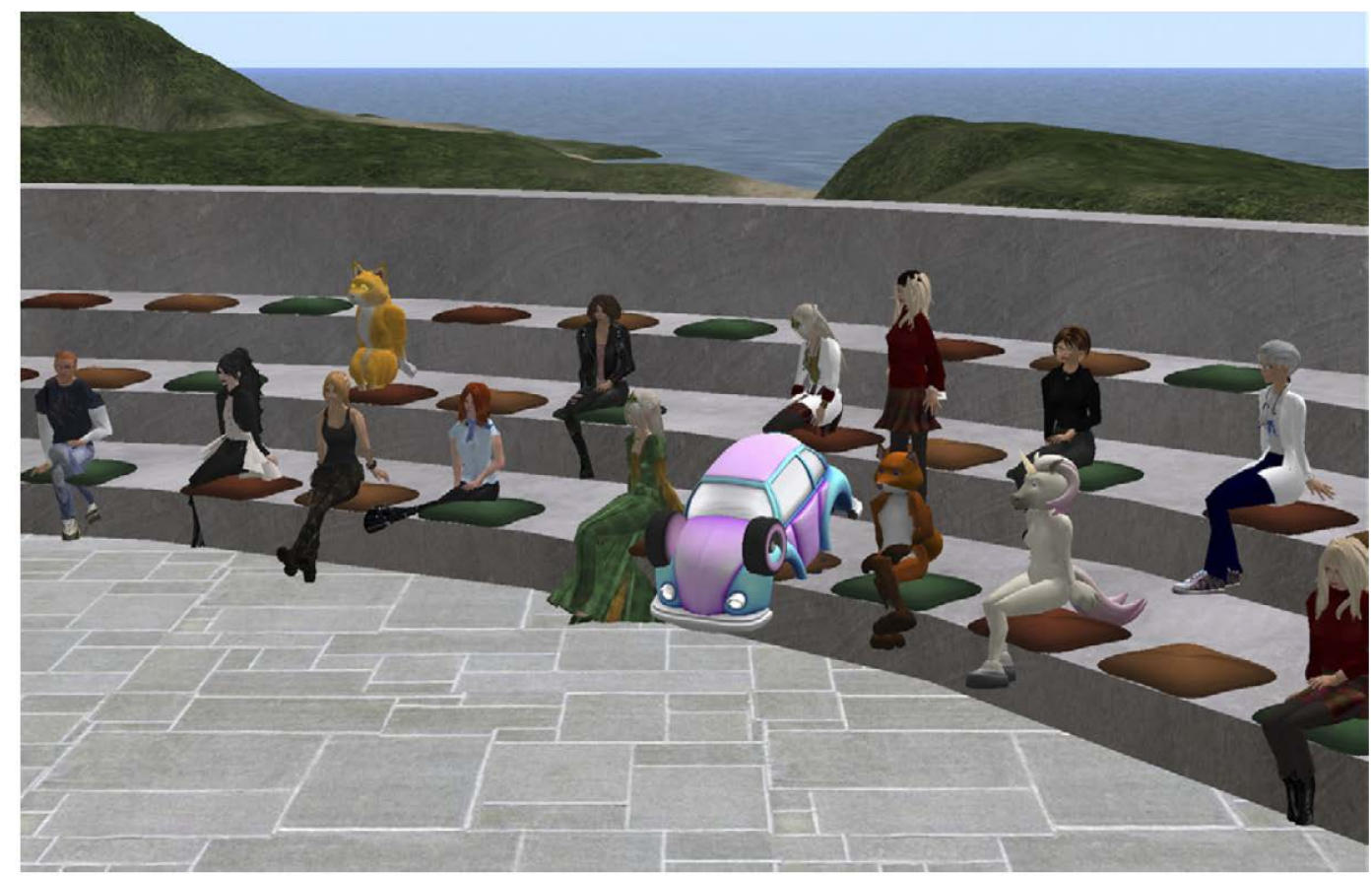

Fig. 3 Participants in SL session. (Courtesy of Sarah Jones.)

participants, (4) embodiment and sense of presence from using an avatar in a 3-D shared space, and (5) highly customizable environment has encouraged adoption of the platform by education programs in the United States and internationally.

A sampling of existing uses of SL for nursing and health care:

- University of Texas (UT) at Arlington College of Nursing Genomics Journal Club. Since September 2010, the Genomics Journal Club, led by the UT at Arlington College of Nursing Genomics Translational Research Lab ${ }^{17}$ science director, Dr Patricia Newcomb, has met in SL as well as face-to-face. ${ }^{18}$

- US Department of Veterans Affairs military amputee support. The Telemedicine and Advanced Technology Research Center (Fort Detrick, MD, USA), in partnership with ADL Company (Bloomington, MN, USA) and Virtual Ability, Inc (Aurora, CO, USA), have used an SL-like virtual environment to address peer support needs of military amputees. ${ }^{19}$

- T2 Virtual PTSD Experience. The National Center for Telehealth and Technology (T2), a component center of the Defense Centers of Excellence for Psychological Health and Traumatic Brain Injury and part of the Military Health System, has created an environment that incorporates simulations and information to educate visitors about combat-related posttraumatic stress disorder (PTSD). ${ }^{20}$

- Virtual Hallucinations. This simulation of a hospital unit incorporates audio and visual elements based on the hallucinations of patients with schizophrenia. Developed as a pilot project, Yellowlees and Cook ${ }^{21}$ found that the simulation helped visitors feel that they gained better understanding of auditory and visual hallucinations after touring the environment.

- The Vanderbilt University School of Nursing. Through a pilot program, the Vanderbilt University School of Nursing is using an SL environment to prepare faculty to manage clinical simulations with their students. ${ }^{22}$ 


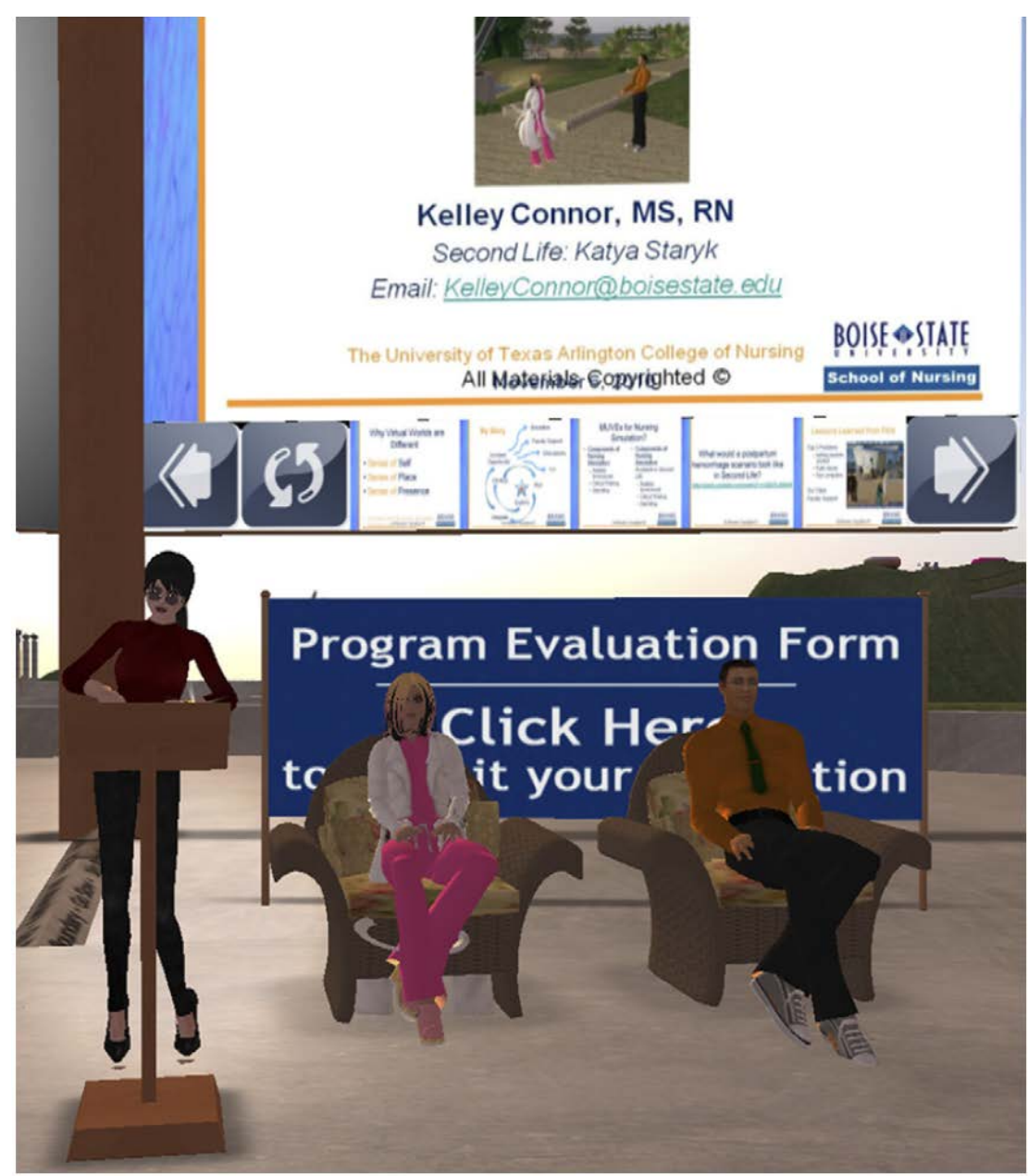

Fig. 4 Workshop moderator introducing speakers. (Courtesy of Sarah Jones.)

\section{DELIVERING A NURSING CONTINUING EDUCATION WORKSHOP IN SECOND LIFE}

In fall 2010, a nursing continuing education workshop (Fig. 4) was held in the virtual world SL through the UT at Arlington Center for Continuing Nursing Education. This workshop was a proof-of-concept project to demonstrate that SL is a platform that can support a quality continuing education experience for nurses to gain multiple benefits without the additional travel time and expense.

The workshop was organized by a planning team, led by Dr Joy Don Baker, which consisted of students in the graduate-level nursing informatics course at the UT Arlington College of Nursing, the Director of the UT Arlington Center for Continuing Nursing Education, the UT Arlington nursing librarian, and the UT Arlington SL coordinator. The planning team was responsible for establishing the learning goals of the workshop, recruiting speakers, setting up the venue, organizing tasks and support roles for the workshop itself, organizing a preworkshop orientation for attendees, promoting the workshop, and ensuring that continuing education units were properly distributed.

The topic chosen for this workshop was The Value of Second Life to Nursing. The team anticipated that most attendees would not be familiar with $\mathrm{SL}$, the current 
education and health care programs offered there, or the particular characteristics of SL that make it a good place for education and health care activities, thus this choice of topic. The program for the workshop consisted of two presentations: viewing of poster session displays of nursing research and an optional tour of a simulation lab in SL. The simulation lab activity was led by one of the workshop speakers. Learning objectives for the workshop were as follows:

At the completion of this educational activity, the participant will be able to:

1. Define virtual learning environments as they relate to nursing education.

2. Recognize the benefits and challenges of using virtual learning environments for continuing nursing education.

3. Identify the key elements for providing continuing nursing education in any environment.

A Web site ${ }^{23}$ was created to accomplish three things: (1) to provide information for prospective and registered attendees, (2) to provide a means for collecting online registrations, and (3) to support publicity efforts for the workshop. Collecting online registrations was important for two reasons. One was simply to know approximately how many people would be attending so that the team could be sure to accommodate the number. Second, preregistration was required for an RN attendee to be able to collect continuing education units upon completion of the workshop. Finally, the registration process included having attendees indicate whether they would be attending a preworkshop orientation to SL. This information allowed the team to plan with Virtual Ability Island staff to provide an optimal orientation experience.

As an adjunct to the workshop, the team provided an opportunity for researchers to set up poster session-type displays of their nursing-related studies. In turn, workshop attendees optionally viewed these displays on a self-guided tour. The

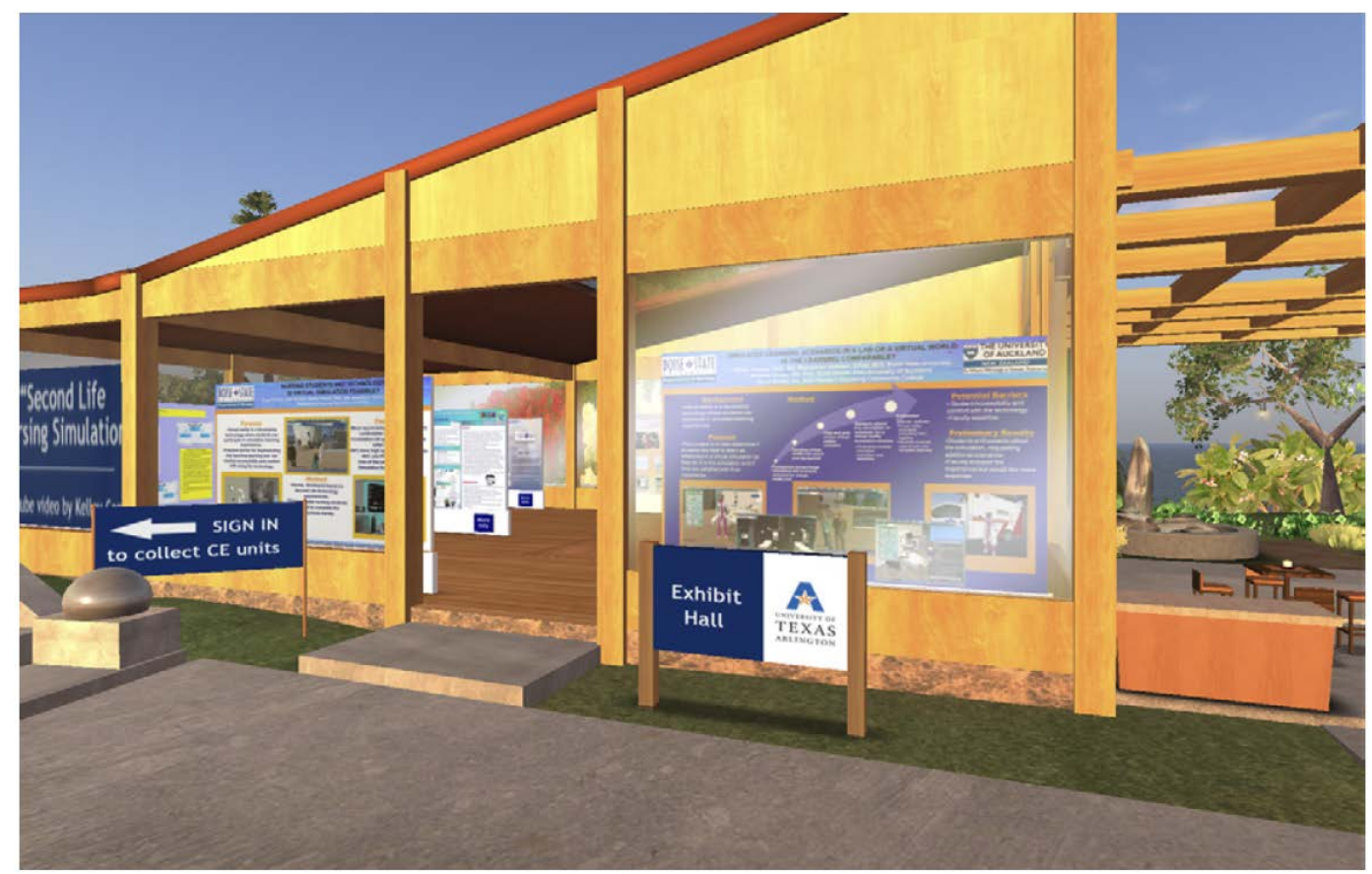

Fig. 5 Poster Presentation exhibit hall in SL. (Courtesy of Sarah Jones.) 
exhibiting researchers were not required to be present to discuss their research. The team set up an exhibit hall (Fig. 5) adjacent to the conference center auditorium for the purpose of housing these displays.

\section{CONSIDERATIONS FOR HOSTING AN EVENT IN SECOND LIFE}

As with hosting an event in a physical-world location or using another online platform such as Web conferencing software, there are logistic considerations that will lead to success with hosting an event in SL. These considerations have to do with (1) features of the event venue, including the location of the event, the features of the virtual land, and the design and usability of the venue buildings; (2) services to support both speakers and event attendees, including preevent orientation and training in the SL software and speaker presentation equipment; and (3) planning designed to make the event itself run smoothly including publicity, preregistration for attendees, support staff for the event, and a process for awarding contact hours to RN attendees. Planning and early ongoing evaluation of each of these elements was an important part of preparation. The logistic elements are described in the following sections.

\section{The SL Location}

The SL platform uses the metaphor of land to define the virtual environments created within it. Associated with this virtual land are technological affordances and limitations that correspond to the computing resources available on the host servers of the platform. Awareness of the limits, in particular, will allow for creating an environment that will support a successful event.

\section{The Land}

In order to maximize the server resources available and to minimize distractions introduced by virtual neighbors, it is recommended that the event be located on a segment of virtual land called a private region, the primary segment of virtual land offered on the SL platform. With one private region an event can comfortably accommodate 30 to 50 attendees, although the limit for the number of avatars per region is 100 . For a larger group or to provide a maximally comfortable experience for speakers and attendees, two contiguous private regions can be used, with the workshop location spanning the two regions. This feature allows the event itself to use the server resources of two regions.

\section{The Venue}

Although an environment in SL can be created to look like anything from a wheat field $^{24}$ to a city ${ }^{25}$ or even a fully functional surgical suite, ${ }^{26}$ it can be helpful for attendees if the space for a continuing education workshop resembles a location they would expect to visit in the physical world. For this workshop, the team designed a conference center consisting of an open-air auditorium and an adjacent building to house poster session exhibits. Features of the conference center included the following:

- Seating for 60 attendees, with animations to help them control their avatar movements - Adequate space to allow avatars to move freely

- An architectural design without obstructed views

- Directional signage

- Other signage to help participants understand the function of various objects and locations, including the continuing education sign-in desk. 
The adjacent exhibit hall accommodated 11 poster session displays, including a multimedia presentation authored by one of the workshop speakers. Because this multimedia presentation included sound, the team used one of the SL features to prevent that display from disturbing the workshop participants by isolating the display's sound while still having it placed in the exhibit hall along with the other poster session displays. The team chose to use two private regions and to have the main auditorium span the two regions. This configuration allowed the team to have available the server resources of both regions for the event.

\section{Optimizing Technology Performance}

In designing a venue, there are steps that can be taken to minimize the server resources required for the event. This optimization helps attendees who may have slower Internet connections or less powerful computers. The steps included minimizing the number of scripts that were used to introduce interactivity into the environment and using best practices such as in the construction of the venue. It is also possible for the manager of the virtual land to remotely restart the server on which the private region resides. Restarting the server additionally helps to ensure a smooth technology experience for the event.

\section{Attendee Orientation}

Although some attendees may be experienced in using SL, others may be new to the platform. Therefore, initial training and orientation can optimize the experience. Analogous to these virtual provisions are new members' or first-time attendees'

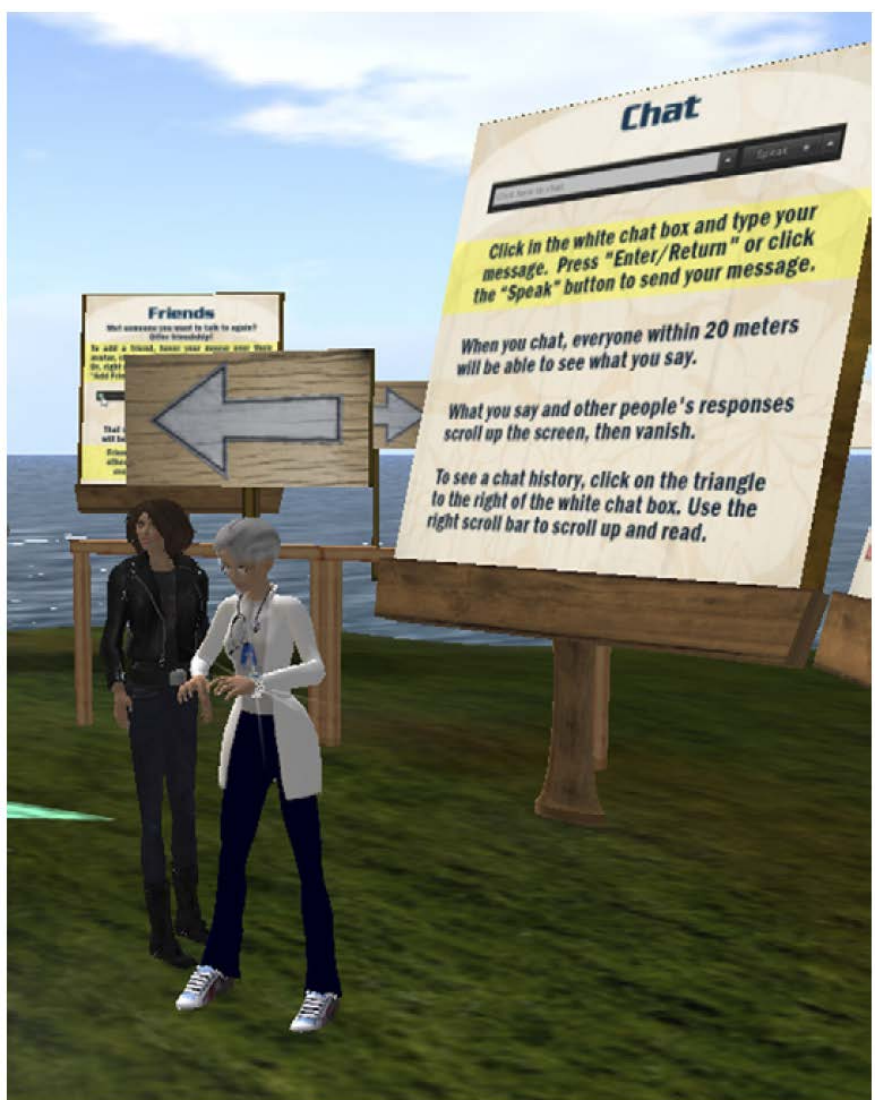

Fig. 6 UT Arlington faculty provide instruction during SL orientation. (Courtesy of Sarah Jones 
tracks, events, and orientations (Fig. 6) offered at conferences in the physical world. Helping individuals new to virtual worlds designed for learning allows for more of their time to be spent actually engaged in the learning experience rather than just in venue management.

The team used a preexisting orientation program that is part of Virtual Ability Island, ${ }^{27}$ which provides a succession of self-directed tutorial stations. The tutorial stations each address a specific skill needed to navigate the virtual world, for example walking and flying, chatting, animating the person's avatar, customizing avatar appearance, and getting and using new items including clothing and other avatar accessories.

The team's workshop participants were met by a group of Virtual Ability mentors who led attendees through the tutorial stations and provided both small group and one-on-one assistance. An hour and a half was allotted to the preworkshop orientation session. Offering a preworkshop orientation session accomplishes three things:

- It encourages attendees to log in to SL at least once before the workshop.

- It provides a structured opportunity for attendees to become familiar with the SL software.

- Attendees are better prepared to take full advantage of the educational offerings that the workshops provide.

\section{Support for Speakers}

As in a physical venue, speakers in a virtual world need to have logistic and technology support for their presentations. The SL analog for this support differs in the specific implementations of this support in two areas (1) ease of use and (2) multimedia presentation tools.

\section{Ease of use}

At the conference center location in $\mathrm{SL}$, the team provided dais seating for the presenters and moderators. Seating the avatars in this way put each avatar into a predetermined, appropriate animation rather than leaving the avatar open to extraneous movements that would be distracting to both the person directing the avatar and the participants who were watching the scene on their computer screens. Similarly, the team provided a podium with an appropriate animation so that the speakers could focus on their talk rather than be distracted by unintended movements of their avatars.

\section{Multimedia presentation tools}

The team provided two types of presentation tools. The primary tool was a screen for PowerPoint-type presentations in SL. With this tool, a presentation could be created using standard presentation software, with the individual slides saved as a separate image. The presentation screen tool allowed for group viewing of the slides as well as letting the presenter move forward and backward through the slide set. The second tool was a media-enabled object designed to function as a Web browser. Web pages displayed on this object were viewable in real time by all participants at the location. In addition, the presentations were browsable by participants at the location. Links on a Web page displayed on this object were clickable by participants at the location, Web pages were scrollable, and all participants at the location could observe this Web browsing in real time. This media-enabled object allowed the speakers to display Web-based multimedia as part of their workshop presentations. 


\section{Event Support Staff}

The team also arranged for the event to have a variety of support staff to ensure a smoothly running workshop. The support staff included five specific roles: moderator, greeters, sign-in registrar, transcribers, and event manager.

\section{Moderator}

A person from the planning team was designated the moderator for the event. This person introduced the speakers, kept track of timing, facilitated the transition between speakers, and moderated the question-and-answer session that followed the main presentations.

\section{Greeters}

Two other individuals functioned as greeters to help attendees know where to go and what to do as they arrived at the workshop.

\section{Sign-in registrar}

To meet the requirements for distributing contact hours awarded to preregistered RNs for attending the workshop, one individual was assigned the task of taking and verifying registration. This function allowed the planning group to verify attendance of the participants.

\section{Transcribers}

SL supports two methods of public communication: text chat and voice chat. The SL software will print text chat into a nearby chat window for a person to read and review. However, for presentations like the ones in this workshop, using voice chat is easier for the presenter (avoiding the effort, typographic errors, and time delay of typing passages of text) and easier for the attendee, with attendees listening in a way that is comparable to a physical world venue. However, to accommodate those who for technological or other reasons are not able to listen to the presentation, the team provided voice-to-text transcribers. One transcriber was assigned to each of the two presenters, and a third transcriber was assigned to the moderator. Besides accommodating those unable to listen to the voice presentations, having transcribers allowed for individuals to have a text record of what was said at the workshop. The SL software allows for saving text chat to a file on the participant's computer.

\section{Event manager}

An event manager was on hand to provide support for various SL technical functions and also generally to watch out for potential difficulties during the workshop.

\section{Publicity}

The planning group took advantage of a variety of publicity opportunities to encourage participation by both current SL residents and nurses new to SL. Among these opportunities were e-mail lists specifically for education uses of SL: the SL Educators mailing list $^{28}$ and the Healthcare Support and Education mailing list. ${ }^{29}$ Notices publicizing the event were sent to those e-mail lists in addition to other, physicalworld- based methods of promotion.

\section{Awarding Contact Hours}

As with any continuing nursing education activity, early planning is the key to success. During the planning, the objectives were identified, content was outlined clearly, and exact number of minutes of the actual educational activity were calculated. In Virtual 
compliance with the 60-minute per contact hour standard, this virtual world activity provided 1.0 contact hour for the nurse participants. Once attendance was verified, each participant received a completion certificate by e-mail.

\section{OUTCOMES OF THE WORKSHOP}

Thirty-one individuals attended the workshop. Of these, 19 RNs received the 1.0 contact hour certificate for their attendance, and the 5 non-RNs received certificates of attendance. Ten others attended who did not preregister and did not receive contact hours or certificates of attendance. Eleven RNs and 2 non-RNs preregistered but did not attend the workshop. Of the 19 RNs who received contact hours, 1 was located in New Zealand, 1 in Massachusetts, and 1 in North Carolina, and the rest were located in Texas. The attendees in Texas included 3 in locations distant from Arlington: 1 in Brownsville, 1 in Allen, and 1 in Spring. Of the 5 non-RNs who received certificates of attendance, 1 was located in Poland, whereas the rest were in the Arlington area.

Although the number of participants was not large, the responses of the 19 RNs and their evaluative feedback were very important. Evaluation was done electronically using a common survey tool. All participants were told in advance that they needed to verify their attendance and complete the evaluation form in order to receive their completion certificate with contact hours.

Overall, participants reported that they achieved the learning objectives and were highly satisfied with the educational experience. Most important, when asked how they would integrate what they learned from this activity into their practice, they responded with specific comments including, "Will look to implement SL activities into my advanced physical assessment course, introduce SL as an alternate continuing education option for staff, explore use in nursing education."

Participants found that the most valuable parts of the activity included visiting the second-floor critical care unit during the activity, having the speakers share their experiences with virtual world leaning, and ability to practice in the New Zealand SIM lab. One participant found that the running chat during the session where the transcribers were capturing the speakers talk was distracting. Other than that, there were no negative comments about the activity, the speakers, the content, or the venue. Participants seemed to benefit from the orientation session that was offered and had very little difficulty learning how to actively participate in the educational session based on the feedback they provided in the evaluation data.

\section{SUMMARY}

Providing continuing nursing education in a way that fully engages the learner and offers valuable skills and knowledge that nurses can apply to their work will always be a challenge. Realizing that there is a need for both sufficient time and planning prior to an event is essential. Using a virtual world as the venue for such continuing education offers many advantages such as no need for travel, a sense of being present, and real-time communication with participants. This learning environment can be an exciting and meaningful adventure to undertake for both participants and educators!

\section{REFERENCES}

1. Dealey MF, Bass M. Professional development: factors that motivate staff. Nurs Manage 1995:26(8):32F-32I. 
2. Schweitzer DJ, Krassa TJ. Deterrents to nurses' participation in continuing professional development: an integrative literature review. J Contin Educ Nurs 2010:41(10): 441-7.

3. American Nurses Association, National Nursing Staff Development Organization. Nursing professional development: scope and standards of practice. Silver Springs (MD): American Nurses Association and National Nursing Staff Development Organization; 2010.

4. Bell MW. Toward a definition of "virtual worlds." Journal of Virtual Worlds Research 2008;1:(1). Available at: http://journals.tdl.org/jvwr/article/view/283/237.

Accessed September 11, 2011.

5. Mayrath MC, Traphagan T, Jarmon L, et al. Teaching with virtual worlds: factors to consider for instructional use of Second Life. Journal of Educational Computing Research 2010;43:(4):403-44.

6. Sung $\mathrm{Y}$, Moon JH, Kang $\mathrm{M}$, et al. Actual self vs. avatar self: the effect of online social situation on self-expression. Journal of Virtual Worlds Research 2011;4:(1). Available at: http://journals.tdl.org/jvwr/article/view/1927/3044. Accessed September 15, 2011.

7. Peachey A. The third place in Second Life: real life community in a virtual world. In: Peachey A, Gillen J, Livingstone D, et al. editors. Researching learning in virtual worlds (human-computer interaction series). London: Springer; 2010. p. 91-110.

8. Whang EW, Taylor K, Cash T. Education and virtual worlds: how identity and presence affect users' experience. In: Tettegah S, Calongne C, editors. Identity, learning and support in virtual environments (educational futures: rethinking theory and practice), vol. 36. Rotterdam (The Netherlands): Sense Publishers; 2009. p. 3344.

9. Jarmon, L. Pedagogy, education and innovation in 3-d virtual worlds. Journal of Virtual Worlds Research 2009;2:(1). Available at: https://journals.tdl.org/jvwr/article/view/639/470. Accessed September 11, 2011.

10. Linden Lab. The Second Life homepage. Available at: http://secondlife.com/. Accessed September 15, 2011.

11. Linden Research, Inc. The Linden Lab homepage. Available at: http://lindenlab.com/.Accessed September 15, 2011.

12. SimTeach. Institutions and organizations in SL: universities, colleges \& schools. Available at: http://www.simteach.com/wiki/index.php?titlelnstitutions_and_Organizations_in_ SL\#UNIVERSITIES.2C_COLLEGES_.26_SCHOOLS. Updated September 15, 2011. Accessed September 15, 2011.

13. Linden BK. Q1 2011 Linden dollar economy metrics up, users and usage unchanged. Available at: http://community.secondlife.com/t5/Featured-News/Q1-2011-LindenDollar-Economy-Metrics-Up-Users-and-Usage/ba-p/856693. Updated May 6, 2011. Accessed September 15, 2011.

14. Castronova E. Synthetic worlds: the business and culture of online games. Chicago: The University of Chicago Press; 2005.

15. Castronova E. Exodus to the virtual world: how online fun is changing reality. New York: Palgrave Macmillan; 2007.

16. Active Worlds, Inc. Active Worlds and education. Available at: http://www.activeworlds.com/edu/. Accessed September 15, 2011.

17. University of Texas at Arlington College of Nursing. Genomics translational research laboratory. Available at: http://www.uta.edu/nursing/genomics/. Accessed September 15, 2011.

18. University of Texas at Arlington in Second Life. Genomics journal club in Second Life. Available at: http://www.uta.edu/secondlife/genomicsjournalclub/. Accessed September 15, 2011. 
19. Thompson D, Fisher A. Amputee Virtual Environment Support Space--a vision for virtual military amputee support. J Rehabil Res Dev 2010;47(6):vii-xii.

20. National Center for Telehealth \& Technology.T2 virtual PTSD experience. Available at: http://t2health.org/vwproj/. Accessed September 15, 2011.

21. Yellowlees PM, Cook JN. Education about hallucinations using an internet virtual reality system: a qualitative study. Acad Psychiatry 2006;30:534-9.

22. Dunigan R. Vanderbilt University introduces new nursing technology. Available at: http://www.newschannel5.com/story/14293876/vanderbilt-introduces-newnursingtechnology. Updated March 22, 2011. Accessed September 15, 2011.

23. University of Texas at Arlington College of Nursing. The value of Second Life to nursing. Available at: http://www.uta.edu/secondlife/nursingce/. Updated November 6, 2011. Accessed September 15, 2011.

24. The Grid Live. The Far Away - a wheat field helping fight poverty. Available at: http://thegridlive.com/2007/12/28/the-far-away-a-wheat-field-helping-fightpoverty/. Updated December 28, 2007. Accessed September 15, 2011.

25. Linden Lab. Destination guide: Dublin. Available at: http://secondlife.com/destination/dublin. Accessed September 15, 2011.

26. Linden Lab. Destination guide: postgraduate medical school. Available at: http:// secondlife.com/destination/postgraduate-medical-school. Accessed September 15, 2011.

27. Virtual Ability, Inc. Virtual Ability. Available at: http://www.virtualability.org. Accessed September 15, 2011.

28. Linden Lab. Educators - SL educators (The SLED list). Available at: https://lists.secondlife.com/cgi-bin/mailman/listinfo/educators. Accessed September 15, 2011.

29. Linden Lab. Healthcare - healthcare support and education. Available at: https://lists.secondlife.com/cgi-bin/mailman/listinfo/healthcare. Accessed September 15, 2011. 